\title{
Bibliometric analysis of bronchopulmonary dysplasia in extremely premature infants in the Web of Science database using CiteSpace software
}

\section{Qin Zhou}

Zhejiang Provincial People's Hospital https://orcid.org/0000-0003-4965-4614

Haibo Kong

Zhejiang Provincial People's Hospital

Baomei He

Zhejiang Provincial People's Hospital

Suya Zhou ( $\nabla$ suya.zhou@163.com )

Hangzhou Children's Hospital https://orcid.org/0000-0003-1046-352X

\section{Research}

Keywords: bronchopulmonary dysplasia, extremely premature infants, bibliometrics, CiteSpace

Posted Date: April 14th, 2021

DOI: https://doi.org/10.21203/rs.3.rs-418353/v1

License: (9) This work is licensed under a Creative Commons Attribution 4.0 International License. Read Full License 


\section{Abstract}

Objectives: To review the literature related to bronchopulmonary dysplasia in extremely premature infants, summarize research hotspots, and report trends.

Methods: Relevant articles from 2008 to 2020 were retrieved from the Web of Science Core Collection database, and we extracted the following data: title, abstract, year, keywords, author, organization, journal and cited literature. We downloaded the data into CiteSpace (version 5.7.R3) to summarize countries, institutions, journals, and authors. We visualized the data with a knowledge map, collaborative network analysis, cluster analysis, and burst keyword analysis.

Results: We identified 610 articles on bronchopulmonary dysplasia in extremely premature infants. The United States had the most articles on this topic (302 articles), followed by Canada (49 articles) and Germany (44 articles). The top three institutions, high-yield journals, and authors were all from the United States. The most common keywords were neurodevelopmental disorders, active perinatal care, mechanical ventilation, inflammation, pulmonary hypertension, low-dose hydrocortisone, development, and patent ductus arteriosus.

Conclusions: This study illustrates the trends and frontiers in the study of bronchopulmonary dysplasia in extremely premature infants. The current hot issues are to identify the high-risk factors of bronchopulmonary dysplasia in extremely premature infants, reasonable hormone use, new cell therapy, and management of complications.

\section{Background}

With the improvement of neonatal treatment, the survival rate of extremely premature infants has increased significantly. Consequently, the incidence of bronchopulmonary dysplasia (BPD) is also increasing. Studies have shown that the incidence of BPD in extremely premature infants with a gestational age of 22 to 27 weeks is $45 \%$ [1]. Although BPD has severe sequelae and a significant mortality rate, there are no effective treatment measures. We conducted a literature review to further understand the research hotspots of bronchopulmonary dysplasia in extremely premature infants and guide targeted research.

Bibliometrics is a text mining and analysis method that summarizes and analyzes research papers and academic journals. CiteSpace(http://cluster.cis.drexel.edu/ cchen/citespace/download/) is a scientific software that is often used to detect and visualize current scientific knowledge, detect trends in the literature, and determine future research directions [2,3]. CiteSpace uses information from the Web of Science Core Collection (WOSCC) and other database networks [4]. This program has been widely used in many fields such as medicine, geology, and ecology [5-7]. It can evaluate the data around knowledge graphs, including authors, journals, research institutions, and keywords. 
As far as we know, bibliometric techniques have not been applied to the area of BPD in extremely premature infants. In this study, we used CiteSpace software to visualize the development trend of BPD in extremely premature infants. We discuss the research directions and hot issues in this field.

\section{Methods}

We used CiteSpace 5.7.R3 for the bibliometrics and visualization analysis, which was designed to provide critical information of the current knowledge for bronchopulmonary dysplasia in extremely premature infants, including the fast-growth topical areas and citation hotspots. The articles were identified from a literature search using the WOSCC.

\section{Search Parameters}

Our retrieval used the following Core Collection of Web of Science(WOS): SCI-EXPANDED, SSCI, A\&HCI, CPCI-S, CPCI-SSH, BKCl-S, BKCl-SSH, ESCl, CCR-EXPANDED, and IC. We performed a Boolean search on two lists with the operator "and." The first list included the following search structure: TS=( Infant, Extremely Premature* OR Extremely Premature Infant* OR Infants, Extremely Premature* OR Premature Infant, Extremely* OR Premature Infants, Extremely* OR Extremely Preterm Infants* OR Extremely Preterm Infant* OR Infant, Extremely Preterm* OR Infants, Extremely Preterm OR Preterm Infant, Extremely* OR Preterm Infants, Extremely* OR Extremely Premature Infants*). The second list included the following search structure: TS= ("Bronchopulmonary Dysplasia" OR "Dysplasia, Bronchopulmonary"). We searched articles (Document Type) in English (Languages) published between 2008 and 2020 (Retrieval time; Retrieval deadline: 2020.12.31).

\section{Data Export}

This retrieved articles, which were then exported using the "other file format," which we defined as "plain text." The exported record content was "full records and cited references."

\section{Analysis}

We used the CiteSpace software to identify the citation bursts for the publication year, country/region, research institution, journal, author, research hotspot, and keywords.

This information was then presented as a knowledge graph using the following parameters: a 13-year period and a time slice of one year. The Term Sources were "Title, Abstract, Author Keywords (DE), and Keywords Plus (ID)". We set the Links parameters are "Strength: Cosine", "Scope: Within Slices".

In the network graph, different nodes represented various elements such as authors, institutions, countries, and keywords, while the size of nodes reflected the number or frequency of publications [8]. Links between nodes showed relationships such as collaboration, co-occurrence, or co-reference [9].

\section{Results}




\section{Publication Years}

We retrieved 610 documents related to BPD in extremely premature infants. The number of related research articles on this topic is proliferating. The number of articles published increased from 18 in 2008 to 64 in 2020, showing that this research continues to develop and is one of the current hotspots in pediatrics. (Fig. 1)

\section{Countries and Institutions Analysis}

We analyzed each country's cooperation network map for this topic (Fig. 2) and used the Web of Science retrieval results to get the top 10 countries by the number of publications (Table 1). The United States has the most significant number of articles, followed by Canada, Germany, and Australia, showing that the countries mentioned above are in a leading position on this topic. The United States has a high national

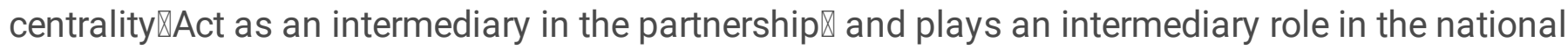
cooperation network. In other countries, centrality is relatively low, which shows that most institutions have a low influence and cooperation.

The top 5 institutions accounted for 320 articles (52.46\%, Table 1$)$. The top 5 research institutions are all in the United States: University of Alabama Birmingham, Case Western Reserve University, RTI International, Brown University, and Emory University. This finding shows that American research institutions are vital in the research field of BPD in extremely premature infants, and they have carried out more in-depth and lasting research on the project with fruitful results. These research institutions have a dense network of cooperation, and they have more collaboration with other institutions (Fig. 3).

Table 1. Top 10 countries and institutes publishing research on BPD in extremely premature infants

\begin{tabular}{llll|lll}
\hline \multicolumn{3}{c|}{ Country Ranking } & \multicolumn{3}{c}{ Institutional ranking } \\
\hline Rank & Country & Publications & Centrality & Rank & Institution & Publications \\
\hline 1 & USA & 302 & 0.42 & 1 & Univ Alabama Birmingham & 46 \\
2 & Canada & 49 & 0.04 & 2 & Case Western Reserve Univ & 35 \\
3 & Germany & 44 & 0.09 & 3 & RTI Int & 34 \\
4 & Australia & 39 & 0.09 & 4 & Brown Univ & 32 \\
5 & Sweden & 34 & 0.08 & 5 & Emory Univ & 32 \\
6 & Japan & 34 & 0.03 & 6 & Duke Univ & 31 \\
7 & England & 32 & 0.18 & 7 & Wayne State Univ E & 30 \\
8 & Italy & 30 & 0.03 & 8 & Eunice Kennedy Shriver Natl Inst & 29 \\
& & & & & Child Hlth \& Hum & \\
9 & Switzerland & 28 & 0.01 & 9 & Univ Penn & 26 \\
10 & France & 24 & 0.08 & 10 & Stanford Univ & 25 \\
\hline
\end{tabular}

\section{Journal and Author Analysis}

Table 2 lists the top ten journals by the number of publications. Among these journals, American journals account for seven, and the remaining three are from European countries. The top ten authors of the 
number of articles published in this field are all Americans (Table 3), indicating the significant research in this field is in the United States.

Table 2. Top 10 journals and published articles on BPD in extremely premature infants

\begin{tabular}{lllll}
\hline Rank & Journal & Publications & IF (2020) & Country \\
\hline 1 & The Journal of Pediatrics & 52 & 3.739 & USA \\
2 & Journal of Perinatology & 37 & 1.581 & USA \\
3 & Pediatrics & 34 & 5.401 & USA \\
4 & American Journal of Perinatology & 28 & 1.581 & USA \\
5 & Acta Paediatrica & 27 & 2.265 & England \\
6 & Neonatology & 26 & 2.554 & Switzerland \\
7 & Pediatric Pulmonology & 22 & 2.801 & USA \\
8 & Early Human Development & 20 & 1.853 & Netherlands \\
9 & Archives of Disease in Childhood. Fetal and Neonatal Edition & 17 & 3.776 & USA \\
10 & Journal of Maternal Fetal Neonatal Medicine & 10 & 1.812 & England \\
\hline
\end{tabular}

Table 3. Top 10 authors with most publications on of BPD in extremely premature infants

\begin{tabular}{clc}
\hline Rank & Author & Publications \\
\hline 1 & Abhik Das & 34 \\
2 & Rosemary D Higgins & 30 \\
3 & Waldemar A Carlo & 30 \\
4 & NamasivayamAmbalavanan & 26 \\
5 & Barbara J Stoll & 21 \\
6 & Abbot R Laptook & 19 \\
7 & Michele C Walsh & 17 \\
8 & Richard A Ehrenkranz & 13 \\
9 & Seetha Shankaran & 13 \\
10 & T Michael O'Shea & 13 \\
\hline
\end{tabular}

\section{Cited Literature and Author Analysis}

Table 4 and Fig. 4 lists the most cited documents in this field. Among these documents, the author, BJ Stoll (Emory University, United States), has the top two papers in terms of the number of citations in this area (Table 4). It shows that he has made outstanding contributions in this research direction. Most of the top five citations are published in the TOP journals: American Journal of Respiratory and Critical Care Medicine (Impact factor [IF]=17.452), JAMA - Journal of the American Medical Association (IF=4.367), New England Journal of Medicine (IF=74.699), and Pediatrics (IF=5.359). This pattern shows that the research results in $\mathrm{BPD}$ in extremely premature infants are of great significance.

Table 4. Top 5 high cited articles related to BPD in extremely premature infants 


\begin{tabular}{|c|c|c|c|}
\hline Rank & Author & Highly cited articles & Frequency \\
\hline 1 & $\begin{array}{c}\text { Stoll } \\
\text { BJ }\end{array}$ & $\begin{array}{l}\text { Trends in Care Practices, Morbidity, and Mortality of Extremely Preterm } \\
\text { Neonates, 1993-20120JAMA-J Am Med Assoc, 2015 }\end{array}$ & 64 \\
\hline 2 & $\begin{array}{c}\text { Stoll } \\
\text { BJ }\end{array}$ & $\begin{array}{l}\text { Neonatal Outcomes of Extremely Preterm Infants from the NICHD Neonatal } \\
\text { Research Network (Pediatrics, 2010) }\end{array}$ & 52 \\
\hline 3 & $\begin{array}{l}\text { Finer } \\
\text { NN }\end{array}$ & $\begin{array}{l}\text { Early CPAP versus Surfactant in Extremely Preterm Infants (New Engl J Med, } \\
\text { 2010) }\end{array}$ & 26 \\
\hline 4 & $\begin{array}{c}\text { Carlo } \\
\text { WA }\end{array}$ & $\begin{array}{l}\text { Target Ranges of Oxygen Saturation in Extremely Preterm Infants } \square \text { New Engl J } \\
\text { Med, 2010) }\end{array}$ & 24 \\
\hline 5 & $\begin{array}{l}\text { Fawke } \\
\quad \mathrm{J}\end{array}$ & $\begin{array}{l}\text { Lung Function and Respiratory Symptoms at } 11 \text { Years in Children Born } \\
\text { Extremely Preterm } \square \text { Am J Resp Crit Care, } 2010 \square\end{array}$ & 23 \\
\hline
\end{tabular}

\section{High-frequency Keywords Analysis}

The differences in high-frequency keywords at different periods show that the focus of research on BPD in extremely premature infants has changed over the years. Before 2016, a significant number of articles on BPD in extremely premature infants looked at an association with intrauterine infections. After 2016, the literature is more focused on treating BPD in extremely premature infants and has increased significantly. Research on therapeutic drugs shifted from early dexamethasone to low-dose hydrocortisone. Caffein, inhaled nitric oxide, mesenchymal stem cells, vitamin D deficiency and supplementation, and others (Table 5), have also become new high-frequency keywords (Fig. 5).

Table 5. High-frequency keywords of BPD in extremely premature infants

\begin{tabular}{|c|c|c|}
\hline Rank & Year & High-frequency keywords \\
\hline 1 & $\begin{array}{l}2008- \\
2010\end{array}$ & $\begin{array}{l}\text { Low birth weight, respiratory distress syndrome, gestational age, chorioamnionitis, early } \\
\text { adrenal insufficiency, endothelial growth factor, surfactant, continuous positive airway } \\
\text { pressure, hypercapnia, pulmonary inflammation, dexamethasone, ventricle Bleeding }\end{array}$ \\
\hline 2 & $\begin{array}{l}2011- \\
2015\end{array}$ & $\begin{array}{l}\text { Low birth weight, respiratory distress syndrome, risk factors, cerebral palsy, necrotizing } \\
\text { enterocolitis, chorioamnionitis, retinopathy, inflammation, surfactants, pulmonary } \\
\text { hypertension, high-frequency oscillatory ventilation, dexamethasone therapy, inhaled monoxide } \\
\text { nitrogen }\end{array}$ \\
\hline 3 & $\begin{array}{l}2016- \\
2020\end{array}$ & $\begin{array}{l}\text { Low birth weight, patent ductus arteriosus, treatment, risk factors, pulmonary hypertension, } \\
\text { surfactants, respiratory distress syndrome, prevention, mechanical ventilation, inflammation, } \\
\text { retinopathy, low-dose hydrocortisone, intraventricular hemorrhage, neurodevelopmental } \\
\text { abnormalities, Active perinatal care, nutrition, necrotizing enterocolitis, chorioamnionitis, } \\
\text { caffeine therapy, inhaled nitric oxide, endothelial growth factor, mesenchymal stem cells, } \\
\text { vitamin D deficiency and supplementation, early adrenal insufficiency }\end{array}$ \\
\hline
\end{tabular}

\section{Keywords with Citation Bursts}

Fig. 6 shows the top 20 keywords with the most substantial citation bursts. The blue line represents the time interval, while the red line shows the period in which a keyword had a burst. The keywords show the forefront of research on this topic. In the study of BPD in extremely premature infants, the keywords with large mutation values that lasted until 2020 are highlighted: high-risk factors, inflammation, low-dose 
hydrocortisone, pulmonary hypertension, and patent ductus arteriosus. These may be the future trend of BPD research in extremely premature infants.

\section{Discussion}

We have analyzed the number of publications, countries, high-impact journals, and authors researching BPD in extremely premature infants. We found that over the last 20 years, countries worldwide have increased research on this topic. The top 10 publications are all in developed countries, with the United States having the highest number of publications, academic institutions, high-impact journals, and authors. It shows that a developed economy with sophisticated medical care has played a vital role in treating extremely premature infants with BPD.

The analysis of the results of both high-frequency keywords and keywords with citation bursts shows that the research focus of BPD in extremely premature infants has changed over time. Since 2008, exploring the high-risk factors of BPD in extremely premature infants has been a research hotspot that has determined that the occurrence of BPD is the result of multiple factors. Gestational age(GA), low birth weight, intrauterine infection, maternal chorioamnionitis, lung inflammation, and respiratory distress syndrome(RDS) are important factors in the pathogenesis of BPD. Since 2016, the interest in the relationship between patent ductus arteriosus(PDA) and BPD has gradually increased. The PDA, with the hemodynamic effects due to the large left-to-right shunt, can cause pulmonary edema, which leads to prolonged mechanical ventilation time and increases the risk of developing BPD [10,11].

Glucocorticoids have always been the most studied and, at the same time, the most controversial class of drugs for treating BPD in extremely premature infants. Based on high-frequency keywords, the research on glucocorticoids has shifted from the early dexamethasone to the low-dose hydrocortisone, which has increased in the keywords of the past five years. Researchers have discovered that low-dose hydrocortisone can reduce the toxic effects in the glucocorticoid receptor-mediated central nervous system [12]. However, the current research is still not relevant to hydrocortisone's efficacy in the prevention and treatment of BPD [13]. Certainly, therefore, the short-term, low-dose dexamethasone regimen is still the most widely used $[14,15]$.

Based on keywords, the enthusiasm for research on hormones has not diminished, indicating that their role remains very controversial. Current studies believe that short-term adverse effects include high blood pressure, hyperglycemia, gastrointestinal bleeding, and gastrointestinal perforation when using hormones in premature infants. The hormones have adverse effects on neurodevelopment, including an increased risk of cerebral palsy [16]. As a result, a high-dose long-term hormone to prevent BPD or as early treatment has been abandoned [17]. Therefore, the use, timing, dosage form, and dosage of BPD hormone therapy in extremely premature infants will still focus on future research.

In terms of other drug treatments for BPD in extremely premature infants, research into caffeine and mesenchymal stem cell treatment has increased significantly in recent years. Most scholars believe that early use of caffeine is beneficial as a treatment of BPD $[18,19]$. Caffeine use within 48 hours of birth can 
allow the removal of the ventilator earlier and reduce the incidence of BPD, PDA, and neurodysplasia [20]. However, recent studies have shown that premature infants treatment with caffeine within 5 days of birth, and the fatality rate is on the rise [21]. Therefore, more research is needed to clarify the starting time and duration of caffeine treatment.

In the past five years, several trials have investigated the treatment of BPD with cell therapy. Mesenchymal stem cells (MSCs) derived from human cord blood have received particular attention due to their easy isolation, low immunogenicity, and anti-inflammatory and repair properties. Four countries, South Korea[22], the United States[23], Spain[24], and China[25], have successfully carried out phase I or II clinical trials of MSCs to treat BPD. Published results show that intravenous or intratracheal injection of MSCs can change the composition of inflammatory factors in airway secretions, reduce lung inflammation and fibrosis, and reduce the severity of BPD; to date, no adverse reactions have been found [26]. However, the mechanism of MSCs in repairing BPD is unclear. Therefore, the study of the pathophysiology of BPD, the use of MSCs for treatment, and transforming cell therapy into clinical use will be important areas of future research.

Research hotspots in the past five years have shown that research has gradually moved toward the complications and prognosis of BPD in extremely premature infants. Neurodevelopmental disorders and pulmonary hypertension(PH) are the two major complications of BPD. The long-term neurodevelopmental outcome of preterm infants with BPD is significantly higher than that of non-BPD preterm infants [27]. Neurodevelopment disorders risk factors include infections, poor growth, birth hypoxia, and later steroid use. Studies have shown that infants treated with dexamethasone have increased motor dysfunction and cerebral palsy incidences but decreased academic performance $[28,29]$. PH is the most severe complication of BPD [30], with an incidence rate of $14-50 \%$ [31]. This complication can progress to pulmonary heart disease(PHD) and significantly affect long-term prognosis. BPD-related PH has a mortality rate of up to $40 \%$ before two years of age [32]. Simultaneously, children with BPD should be followed after discharge from the hospital to evaluate the treatments' long-term consequences.

\section{Strengths And Limitations}

To our knowledge, this is the first study to use the co-occurrence and co-citation analysis methods by CiteSpace to perform bibliometric analysis and visual display of bronchopulmonary dysplasia in extremely premature infants.

Our study does have limitations. We analyzed only English studies in the WOS due to software limitations. Therefore, the data may not be comprehensive, and our results may not be applicable to research published in other languages. Synonyms, when clustering keywords, can cause some overlaps between different categories of contents.

\section{Conclusions}


We can determine the research status of BPD treatments and pathophysiology using CiteSpace. Hotspot changes in extremely premature infants can be clearly and intuitively displayed as well. BPD in extremely premature infants is a long-term research topic. Understanding the pathogenesis and treatment prospects of BPD in the future requires continuously discovering and solving related problems. At present, the research hotspots of BPD tend to be the rational use of hormones, cell therapy, early detection, and follow-up of complications. Preventing BPD is far more important than treatment. Research should guide clinicians as to how to prevent BPD and lung injuries. Basic science should study every aspect of the pathogenesis of BPD. The ultimate goal is to stop BPD before it occurs.

\section{Abbreviations}

BPD : bronchopulmonary dysplasia; WOSCC : Web of Science Core Collection; WOS: Web of Science; JAMA: Journal of the American Medical Association; GA :Gestational age; RDS: respiratory distress syndrome; PDA: patent ductus arteriosus; MSCs: Mesenchymal stem cells; PH: pulmonary hypertension; PHD: pulmonary heart disease

\section{Declarations}

\section{Acknowledgements}

We would like to thank TopEdit (www.topeditsci.com) for English language editing of this manuscript.

\section{Authors' contributions}

QZ and SZ designed the research subject. HK and QZ conducted literature retrieval and screening, and BH and HK provided guidance in statistical analysis. QZ wrote the manuscript. SZ critically revised the manuscript. All authors read and approved the final manuscript.

\section{Availability of data and materials}

All data generated or analyzed during this study are included in this published article.

\section{Ethics approval and consent to participate}

Not applicable.

\section{Consent for publication}

Not applicable.

\section{Competing interests}

The authors declare that they have no competing interests. 


\section{Author details}

${ }^{1}$ Department of Pediatrics, Zhejiang Provincial People's Hospital, People's Hospital of Hangzhou Medical College, Hangzhou,310014, China, ${ }^{2}$ Department of Neonatology, Hangzhou Children's Hospital, Hangzhou, 310014, China.

\section{References}

1. Stoll BJ, Hansen NI, Bell EF, Walsh MC, Carlo WA, Shankaran S, et al. Trends in Care Practices, Morbidity, and Mortality of Extremely Preterm Neonates, 1993-2012. JAMA. 2015;314(10):1039-51.

2. Yao L, Hui L, Yang Z, Chen $X$, Xiao A. Freshwater microplastics pollution: Detecting and visualizing emerging trends based on Citespace II. Chemosphere. 2020;245:125627.

3. Chen $\mathrm{C}$. Searching for intellectual turning points: progressive knowledge domain visualization. Proc Natl Acad Sci U S A. 2004;101(Suppl 1):5303-10.

4. Gao Y, Shi S, Ma W, Chen J, Cai Y, Ge L, et al. Bibliometric analysis of global research on PD-1 and PD-L1 in the field of cancer. Int Immunopharmacol. 2019;72:374-84.

5. Mund M, Kloft B, Bundschuh M, Klingelhoefer D, Groneberg DA, Gerber A. Global research on smoking and pregnancy-a scientometric and gender analysis. Int J Environ Res Public Health. 2014;11(6):5792-806.

6. Dufault B, Klar N. The quality of modern cross-sectional ecologic studies: a bibliometric review. Am J Epidemiol. 2011;174(10):1101-7.

7. Zheng M, Fu HZ, Ho YS. Research trends and hotspots related to ammonia oxidation based on bibliometric analysis. Environ Sci Pollut Res Int. 2017;24(25):20409-21.

8. Liang C, Luo A, Zhong Z. Knowledge mapping of medication literacy study: A visualized analysis using CiteSpace. SAGE Open Med. 2018;6:2050312118800199.

9. Chen C, Chen Y. Searching for clinical evidence in CiteSpace. AMIA Annu Symp Proc. 2005:121-5.

10. El-Khuffash A, James AT, Corcoran JD, Dicker P, Franklin O, Elsayed YN, et al. A Patent Ductus Arteriosus Severity Score Predicts Chronic Lung Disease or Death before Discharge. J Pediatr. 2015;167(6):1354-61 e2.

11. Clyman RI, Hills NK, Liebowitz M, Johng S. Relationship between Duration of Infant Exposure to a Moderate-to-Large Patent Ductus Arteriosus Shunt and the Risk of Developing Bronchopulmonary Dysplasia or Death Before 36 Weeks. Am J Perinatol. 2020;37(2):216-23.

12. Noguchi KK. Glucocorticoid Induced Cerebellar Toxicity in the Developing Neonate: Implications for Glucocorticoid Therapy during Bronchopulmonary Dysplasia. Cells. 2014;3(1):36-52.

13. Lim G, Lee BS, Choi YS, Park HW, Chung ML, Choi HJ, et al. Delayed Dexamethasone Therapy and Neurodevelopmental Outcomes in Preterm Infants with Bronchopulmonary Dysplasia. Pediatr Neonatol. 2015;56(4):261-7. 
14. Doyle LW, Davis PG, Morley CJ, McPhee A, Carlin JB. Low-dose dexamethasone facilitates extubation among chronically ventilator-dependent infants: a multicenter, international, randomized, controlled trial. Pediatrics. 2006;117(1):75-83.

15. Doyle LW, Cheong JL, Ehrenkranz RA, Halliday HL. Late ( 7 days) systemic postnatal corticosteroids for prevention of bronchopulmonary dysplasia in preterm infants. Cochrane Database Syst Rev. 2017;10:CD001145.

16. Doyle LW, Cheong JL, Ehrenkranz RA, Halliday HL. Early (< 8 days) systemic postnatal corticosteroids for prevention of bronchopulmonary dysplasia in preterm infants. Cochrane Database Syst Rev. 2017;10:CD001146.

17. Jefferies AL. Postnatal corticosteroids to treat or prevent chronic lung disease in preterm infants. Paediatr Child Health. 2012;17(10):573-4.

18. Schmidt B, Roberts RS, Davis P, Doyle LW, Barrington KJ, Ohlsson A, et al. Caffeine therapy for apnea of prematurity. N Engl J Med. 2006;354(20):2112-21.

19. Schmidt B, Roberts RS, Davis P, Doyle LW, Barrington KJ, Ohlsson A, et al. Long-term effects of caffeine therapy for apnea of prematurity. N Engl J Med. 2007;357(19):1893-902.

20. Lodha A, Seshia M, McMillan DD, Barrington K, Yang J, Lee SK, et al. Association of early caffeine administration and neonatal outcomes in very preterm neonates. JAMA Pediatr. 2015;169(1):33-8.

21. Amaro CM, Bello JA, Jain D, Ramnath A, D'Ugard C, Vanbuskirk S, et al. Early Caffeine and Weaning from Mechanical Ventilation in Preterm Infants: A Randomized, Placebo-Controlled Trial. J Pediatr. 2018;196:52-7.

22. Preterm Infants. A Randomized, Placebo-Controlled Trial.2018.J Pediatr.196(52 - 7.

23. Efficacy. and Safety Evaluation of Pneumostem Versus a Control Group for Treatment of BPD in Premature Infants. ClinicalTrials.gov Identifier: NCT01828957.

24. Safety. and Efficacy of PNEUMOSTEM in Premature Infants at High Risk for Bronchopulmonary Dysplasia (BPD) - a US Study. ClinicalTrials.gov Identifier: NCT02381366.

25. Mesenchymal Stem. Cell Therapy for Bronchopulmonary Dysplasia in Preterm Babies. ClinicalTrials.gov Identifier:NCT02443961.

26. Stem Cells for Bronchopulmonary Dysplasia. ClinicalTrials.gov Identifier: NCT03378063.

27. Namba F.Mesenchymal stem cells for the prevention of bronchopulmonary dysplasia. 2019.Pediatr Int.61(10):945-50.

28. Smith VC, Zupancic JA, McCormick MC, Croen LA, Greene J, Escobar GJ, et al. Rehospitalization in the first year of life among infants with bronchopulmonary dysplasia. J Pediatr. 2004;144(6):799803.

29. Doyle LW, Halliday HL, Ehrenkranz RA, Davis PG, Sinclair JC. An update on the impact of postnatal systemic corticosteroids on mortality and cerebral palsy in preterm infants: effect modification by risk of bronchopulmonary dysplasia. J Pediatr. 2014;165(6):1258-60. 
30. Yeh TF, Chen CM, Wu SY, Husan Z, Li TC, Hsieh WS, et al. Intratracheal Administration of Budesonide/Surfactant to Prevent Bronchopulmonary Dysplasia. Am J Respir Crit Care Med. 2016;193(1):86-95.

31. Krishnan U, Feinstein JA, Adatia I, Austin ED, Mullen MP, Hopper RK, et al. Evaluation and Management of Pulmonary Hypertension in Children with Bronchopulmonary Dysplasia. J Pediatr. 2017; 188:24-34 e1.

32. Mourani PM, Abman SH. Pulmonary Hypertension and Vascular Abnormalities in Bronchopulmonary Dysplasia. Clin Perinatol. 2015;42(4):839-55.

33. Arjaans S, Zwart EAH, Ploegstra MJ, Bos AF, Kooi EMW, Hillege HL, et al. Identification of gaps in the current knowledge on pulmonary hypertension in extremely preterm infants: A systematic review and meta-analysis. Paediatr Perinat Epidemiol. 2018;32(3):258-67.

\section{Figures}

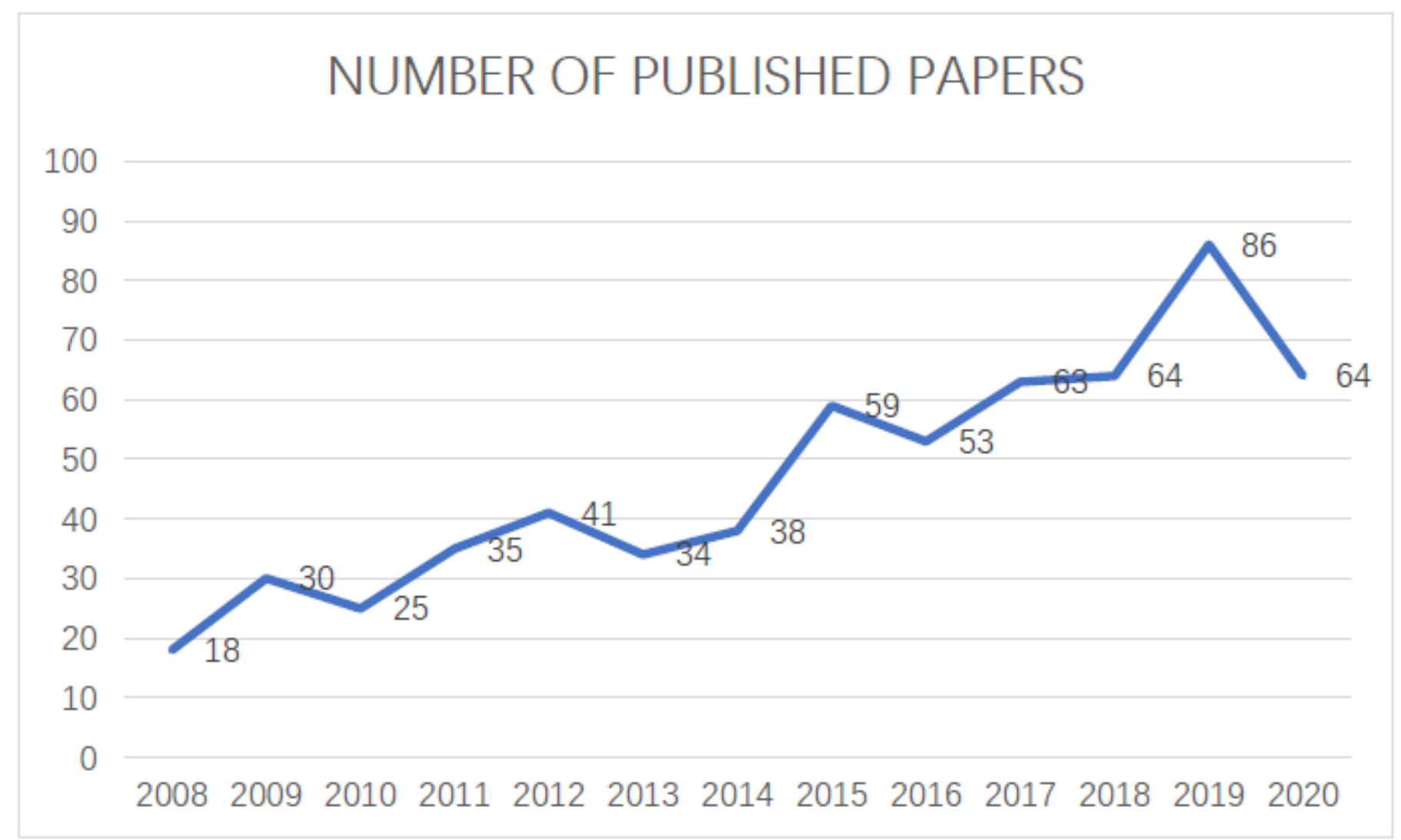

\section{Figure 1}

Trend chart of the number of articles published on BPD in extremely premature infants 
CiteSpace, v. 5.7.R3 (64.bit)

February 24, $20219: 31: 39$ PM CST

WoS: C:IUsersIXIAOIDeshtoplshujuldata

Ti mespan: 2008-2020 (Slice Length=1)

Selection Criteria: $g$-index $(k=25), \mathrm{LRF}=3.0, \mathrm{LBY}=5, e=1.0$

Network: $N=48, E=260$ (Density $=0.2305$ )

Largest CC: $40(83 \%)$

Nodes Labeled: $1.0 \%$

Pruning: None

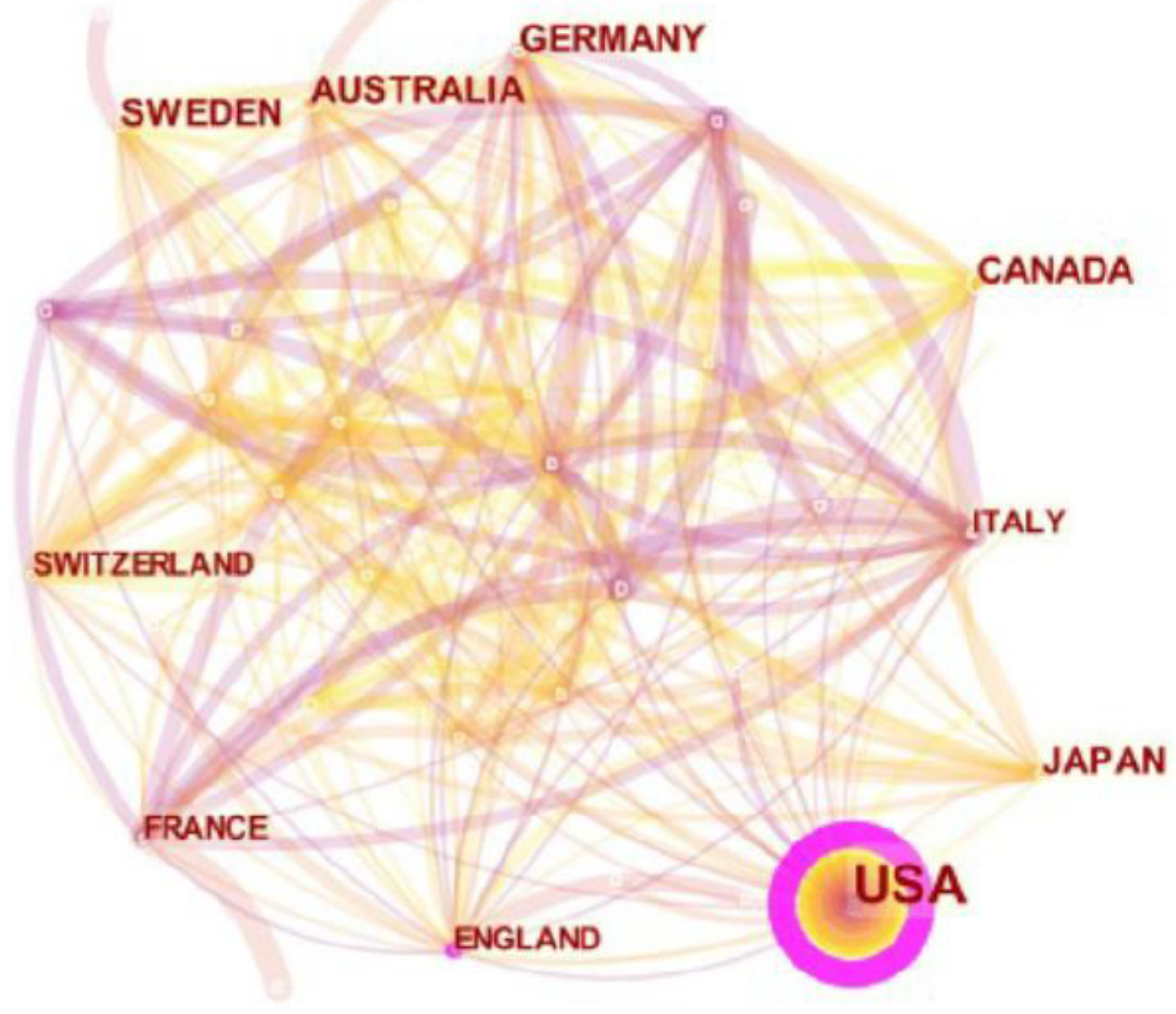

Figure 2

Top 10 collaboration network of country on BPD in extremely premature infants 


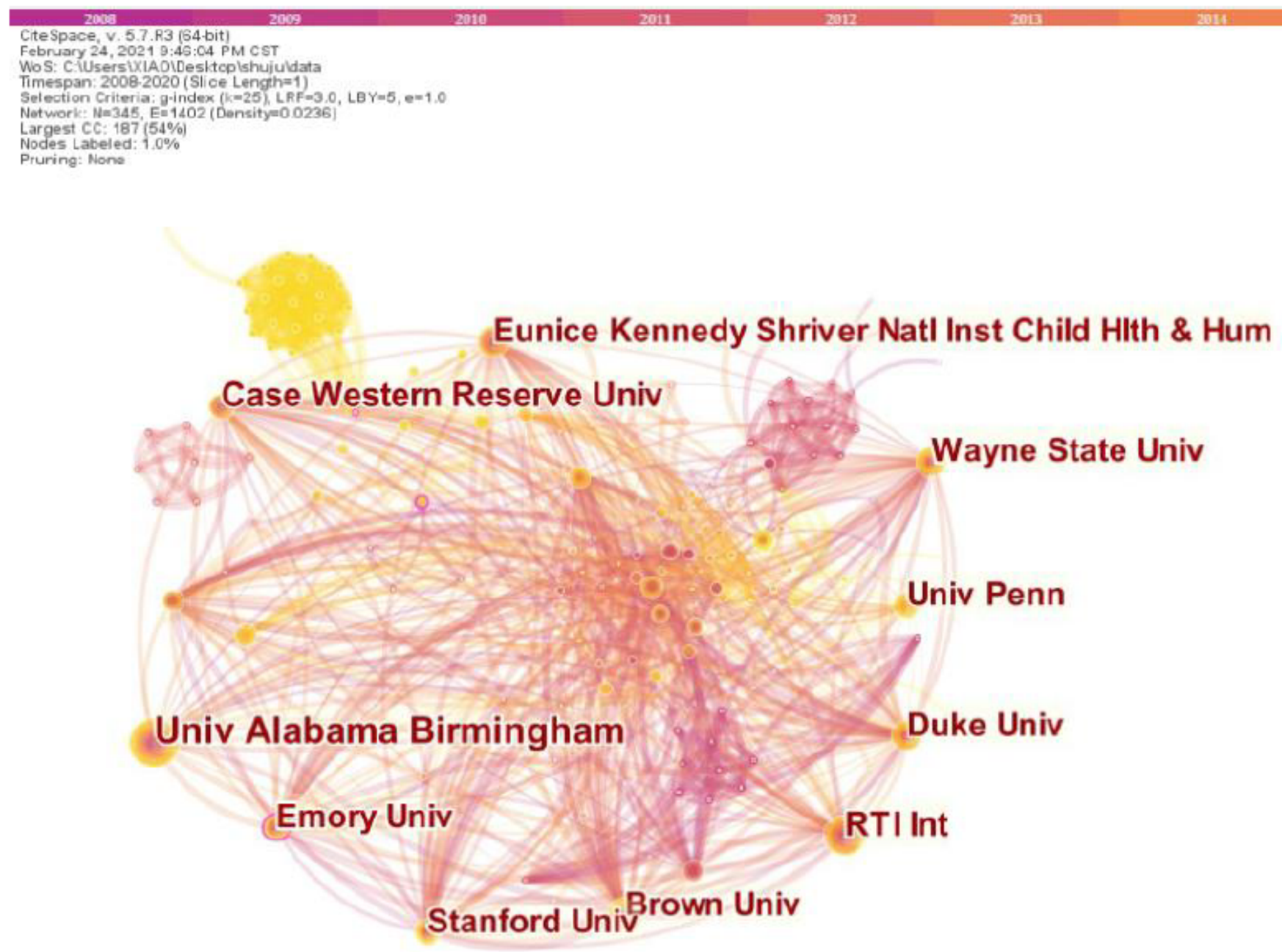

Figure 3

Top 10 collaboration network of institution on BPD in extremely premature infants 


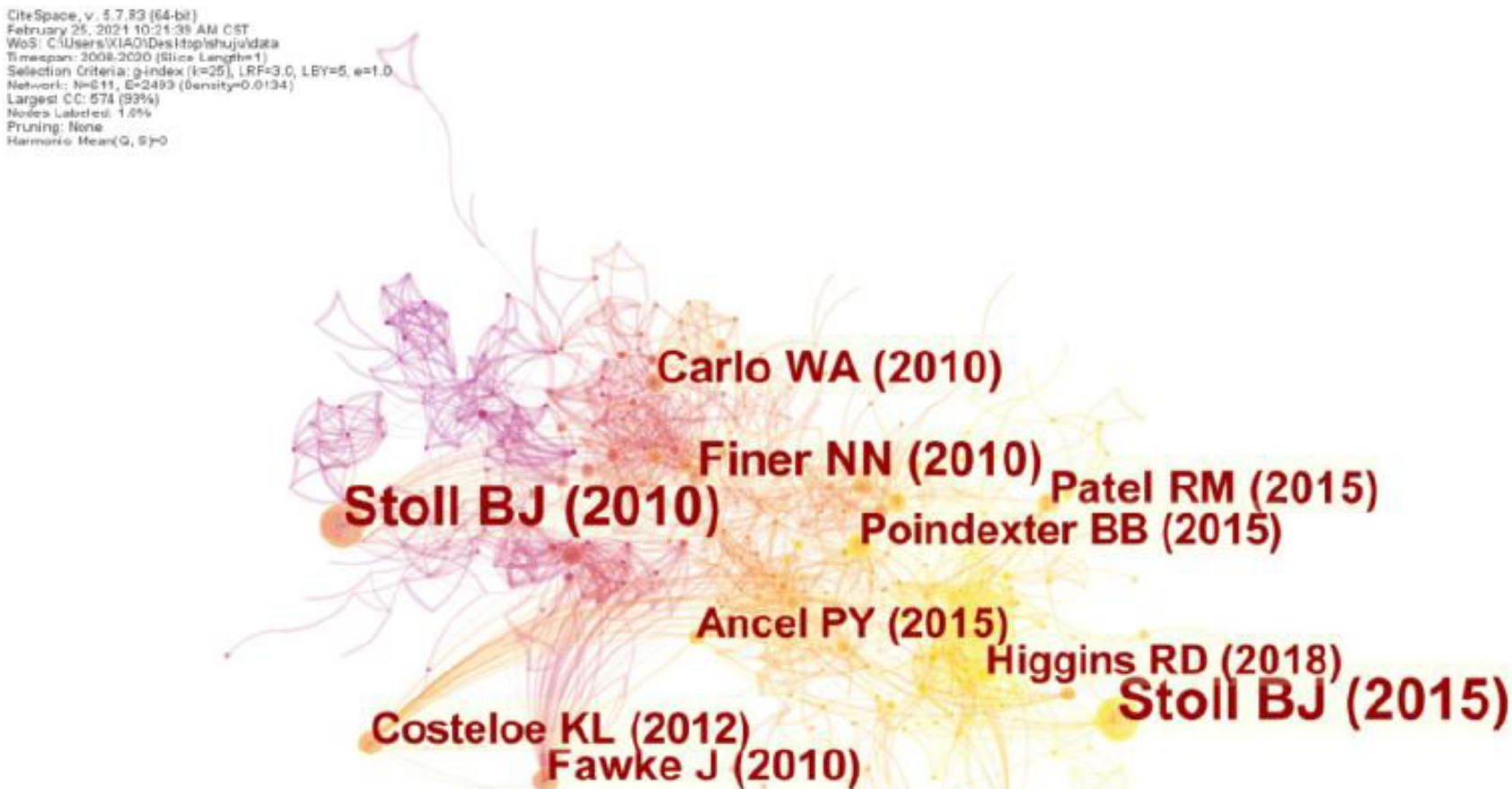

Fawke J (2010)

Figure 4

Top 10 highly cited articles on BPD in extremely premature infants 


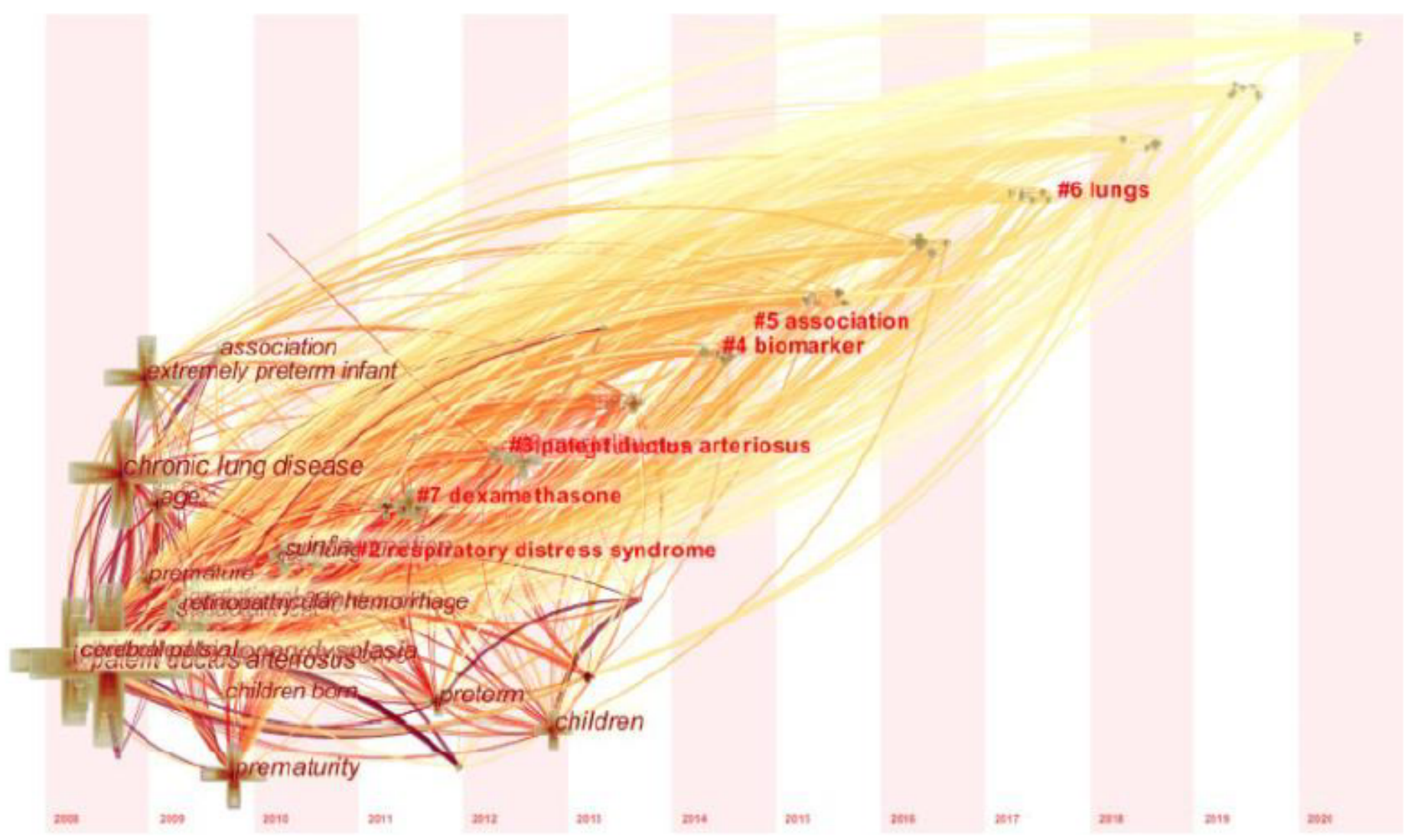

\section{Figure 5}

Timeline-zone of Keywords on BPD in extremely premature infants 


\section{Top 20 Keywords with the Strongest Citation Bursts}

\begin{tabular}{llrll}
\multicolumn{1}{c}{ Keywords } & Year & Strength & Begin & End \\
intensive care & 2010 & 2.6758 & $\mathbf{2 0 1 0}$ & 2015 \\
gestational age & 2010 & 3.7081 & $\mathbf{2 0 1 0}$ & 2013 \\
respiratory distress syndrome & 2010 & 3.304 & $\mathbf{2 0 1 1}$ & 2014 \\
premature & 2010 & 2.2542 & $\mathbf{2 0 1 1}$ & 2015 \\
gestation & 2010 & 2.7993 & $\mathbf{2 0 1 2}$ & 2013 \\
impact & 2010 & 2.2445 & $\mathbf{2 0 1 3}$ & 2017 \\
\hline necrotizing enterocoliti & 2010 & 2.0565 & $\mathbf{2 0 1 4}$ & 2015 \\
\hline newborn & 2010 & 1.9631 & $\mathbf{2 0 1 4}$ & 2016 \\
\hline hemorrhage & 2010 & 2.8917 & $\mathbf{2 0 1 5}$ & 2017 \\
therapy & 2010 & 1.958 & $\mathbf{2 0 1 6}$ & 2017 \\
extremely premature infant & 2010 & 3.0369 & $\mathbf{2 0 1 6}$ & 2018 \\
\hline lung function & 2010 & 1.8922 & $\mathbf{2 0 1 6}$ & 2017 \\
\hline association & 2010 & 2.8087 & $\mathbf{2 0 1 7}$ & 2020 \\
\hline patent ductus arteriosus & 2010 & 2.3543 & $\mathbf{2 0 1 7}$ & 2020 \\
\hline definition & 2010 & 2.5912 & $\mathbf{2 0 1 7}$ & 2018 \\
\hline prevention & 2010 & 3.461 & $\mathbf{2 0 1 7}$ & 2018 \\
\hline pulmonary hypertension & 2010 & 2.3476 & $\mathbf{2 0 1 8}$ & 2020 \\
\hline low dose hydrocortisone & 2010 & 2.3578 & $\mathbf{2 0 1 8}$ & 2020 \\
\hline inflammation & 2010 & 1.9377 & $\mathbf{2 0 1 8}$ & 2020 \\
\hline risk & 2010 & 2.5729 & $\mathbf{2 0 1 8}$ & 2020 \\
\hline
\end{tabular}

突显词图谱

Figure 6

Burstness map of keywords on BPD in extremely premature infants 